\title{
Rancang Bangun Visual Docking Guidance System (VDGS) sebagai Pendeteksi Arah Gerak Longitudinal Pesawat pada Sistem Parkir Pesawat Terbang
}

\author{
Denny Dermawan*, Paulus Setiawan, Agus Basukesti, Riski Nur Muhammad \\ Program Studi Teknik Elektro, Institut Teknologi Dirgantara Adisutjipto, Yogyakarta \\ *email: dennydermawanstta@gmail.com
}

\begin{abstract}
The growth of air transportation and technological developments is getting faster every year. This causes airport services to exceed the ability to provide facilities to meet growth adequately. In this case, it cannot be denied that there are always undesirable things that happen unexpectedly such as airplane accidents which are not only always in the air when flying, there are also many cases of plane accidents at the ground whether it's at the landing or parking process. Therefore, a Visual Docking Guidance System (VDGS) tool was designed using the TF Mini LiDAR sensor and programmed for the aircraft parking system at the airport to identify and guide pilots to find the right position when parking. This tool is able to give guidance information on the aircraft position. A $3<$ sign that is, the plane must move to the left, the $\gg>>$ sign, the plane must move to the right and the // sign as an indicator the aircraft is in the middle position of parking stand. The results showed that the Visual Docking Guidance System (VDGS) using the LiDAR sensor with a distance specification of $10 \mathrm{~m}$ is a fairly good level of accuracy and the error obtained from testing the distance measurement tool and actual distance has an error of 0-0,7368\% with an average error of $0.0972 \%$.
\end{abstract}

Keywords: Visual Docking Guidance System, LiDAR sensor, parking stand.

\section{Pendahuluan}

Sejalan dengan perkembangan jaman dan kemajuan teknologi yang semakin tahun semakin pesat, hal ini menyebabkan pelayanan bandar udara melampaui kemampuan dalam menyediakan fasilitas untuk memenuhi pertumbuhan secara memadai [1]. Sebagian besar sistem transportasi udara di bandar udara ditekan melebihi kemampuan kapasitas rancangan bandar udara yang telah ada, sehingga mengakibatkan memburuknya pelayan di bandar udara [2].

Dalam transportasi udara, perhatian sangatlah khusus diberikan pada pergerakan kemajuan pesawat terbang, kenyamanan penumpang, dan keamanan barang baik melalui bandar udara maupun sistem penerbangan [3]. Demikian gambaran keadaan yang ada di bandara-bandara besar di Indonesia. Karena pertumbuhan transportasi udara semakin tahun semakin pesat [4].

Di setiap bandar udara banyak kegiatan yang dilakukan, untuk melakukan tugas dan fungsi dari kegiatan yang ada di bandar udara, pihak pengelola bandar udara membentuk beberapa divisi, Dinas maupun unit pelayanan untuk mengelola suatu bandar udara [5]. Salah satu unit pelayanan bandar udara tersebut adalah Apron Movement Control (AMC). Divisi ini berada di bawah naungan Dinas operasi bandar udara dan dipimpin oleh asisten manajer sisi udara [6]. Unit ini mempunyai peran yang sangat penting dalam menyelenggarakan pelayanan yang aman dan nyaman bagi setiap perusahaan yang bergerak dibidang transportasi udara.

Dalam hal ini, tidak dapat dipungkiri bahwa pasti selalu ada hal-hal yang tidak diinginkan yang terjadi tanpa diduga-duga yang dapat mengganggu keamanan dan kenyamanan setiap maskapai entah itu dari hal-hal biasa sampai hal-hal yang dapat mengancam 
nyawa pelanggan maskapai tersebut seperti adanya kesalahan hingga mengakibatkan kecelakaan pesawat saat terbang hingga bisa memakan korban jiwa.

Namun kenyataannya, kecelakaan pesawat tidak hanya selalu berada di atas udara pada saat terbang, ternyata ada banyak juga kasus yang tentang kecelakaan pesawat pada saat di darat entah itu pada saat landing hingga sampai ke proses parking. Seperti contoh yang terjadi pada pesawat Lion Air dengan nomor penerbangan JT-633 tujuan Jakarta - Bengkulu yang menabrak tiang bendera pada hari rabu tanggal 7 November 2018 yang lalu [7]. Selanjutnya ada Pesawat Lion Air Boieng-737 900 ER dengan nomor penerbangan JT-358 yang mana bersenggolan di parkiran dengan pesawat jenis yang sama dengan nomor penerbangan JT-796 pada Februari 2011 di bandara Soekarno-Hatta [8]. Banyak orang yang berspekulasi tentang penyebab dari kecelakaan tersebut yang mana jika di simpulkan hal tersebut tidak akan lari dari penjelasan tentang System Eror atau Human Eror.

Dari sinilah didapat ide membuat penelitian ini yaitu dengan menggunakan rancangan Visual Docking Guidance System, dengan harapan dapat mengurangi tingkat kecelakaan pesawat di darat terutama pada saat proses parking, dan tujuan keduanya ialah dengan alat ini di harapkan akan mengurangi penggunaan tenaga manusia dalam proses yang berkaitan, yang mana hal ini juga bertujuan untuk menekan nilai Human Eror dalam pelaksanaan kegiatan penerbangan. Apalagi di jaman sekarang dengan semakin berkembangnya teknologi tidak menuntut kemungkinan pada bandar udara untuk ke depannya, setiap pesawat terbang yang akan parkir di parking stand tidak lagi menggunakan marshaller namun menggunakan peralatan yang semakin canggih [9]. Inilah perlunya Rancangan Visual Docking Guidance System untuk Parking Stand Pesawat terbang.

\section{Metode Penelitian}

Diagram alir penelitian berdasarkan Gambar 1. Perancangan perangkat keras dan lunak dalam sistem ini terdiri dari beberapa modul. Modul tersebut adalah Personal Computer, modul tampilan dalam hal ini panel Ledp10, dan modul sensor lidar yang berupa pemancar dan penerima sinar laser. Modul ini juga terintegrasi dengan motor stepper serta modul mikrokontroler Arduino uno. Di dalam mikrokontroler terdapat program yang mengatur gerak motor stepper, program yang mengatur cara kerja Lidar serta program tampilan dari panel LED. Mikrokontroler mengatur pengambilan data yang di dapat oleh sensor, menghitung nilai waktu dari saat gelombang mulai dipancarkan sampai diterima kembali, memproses data dari sensor lidar kemudian data yang di proses ditampilkan ke panel LedP10.

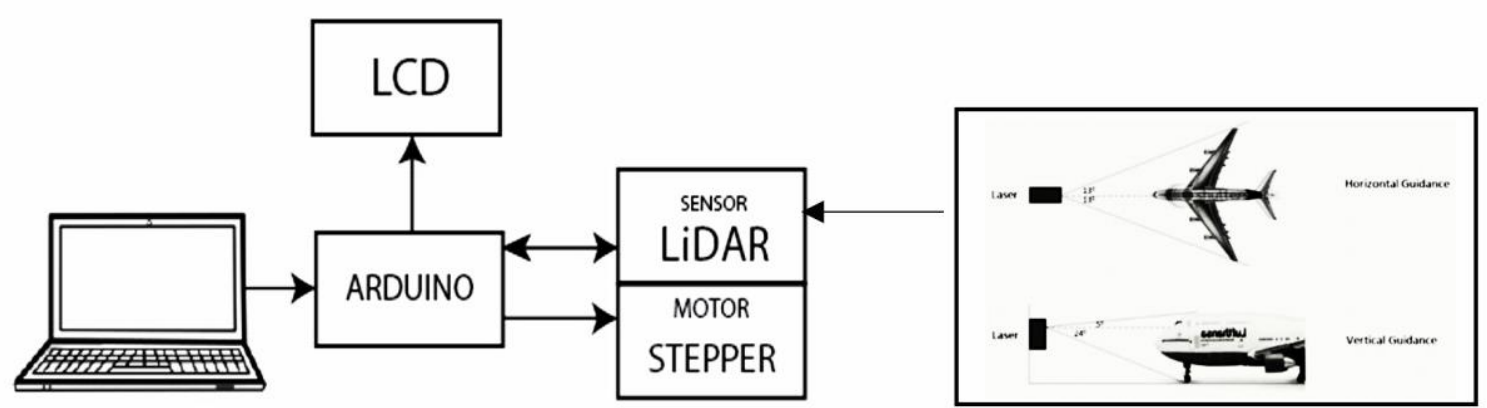

Gambar 1. Diagram Alir Metode Penelitian 


\subsection{Perancangan Alat}

Perancangan alat harus sesuai dengan perkiraan perancangan sistem di mana terdapat sebuah Arduino Mega sebagai mikrokontroler yang akan terintegrasi dengan modul-modul lain seperti panel LED P10, sensor LiDAR, dan Motor yang berfungsi sebagai lengan dari sensor untuk mengarahkan sensor ke media yang akan diukur yaitu 6 titik pengamatan dari kedua sayap pesawat yaitu titik kiri 1(L1), titik kiri 2 (L2), titik kiri 3 (L3), lalu titik kanan 1 (R1), titik kanan 2 (R2), dan titik kanan 3 (R3). Data jarak yang tertangkap oleh sensor tersebut akan diproses oleh arduino dan hasil dari data yang diproses akan ditampilkan pada panel LED P10 yang berupa simbol arah kanan $\gg \gg>$, kiri $<<<<$, dan tengah $/ / \backslash$ yang demikian memberikan instruksi pada pilot untuk mengatur arah gerak pesawat agar dapat posisi yang pas di parkir stand. Gambar perencanaan perancangan alat ditunjukan pada Gambar 2 dan gambar skematik alat ditunjukkan pada Gambar 3.

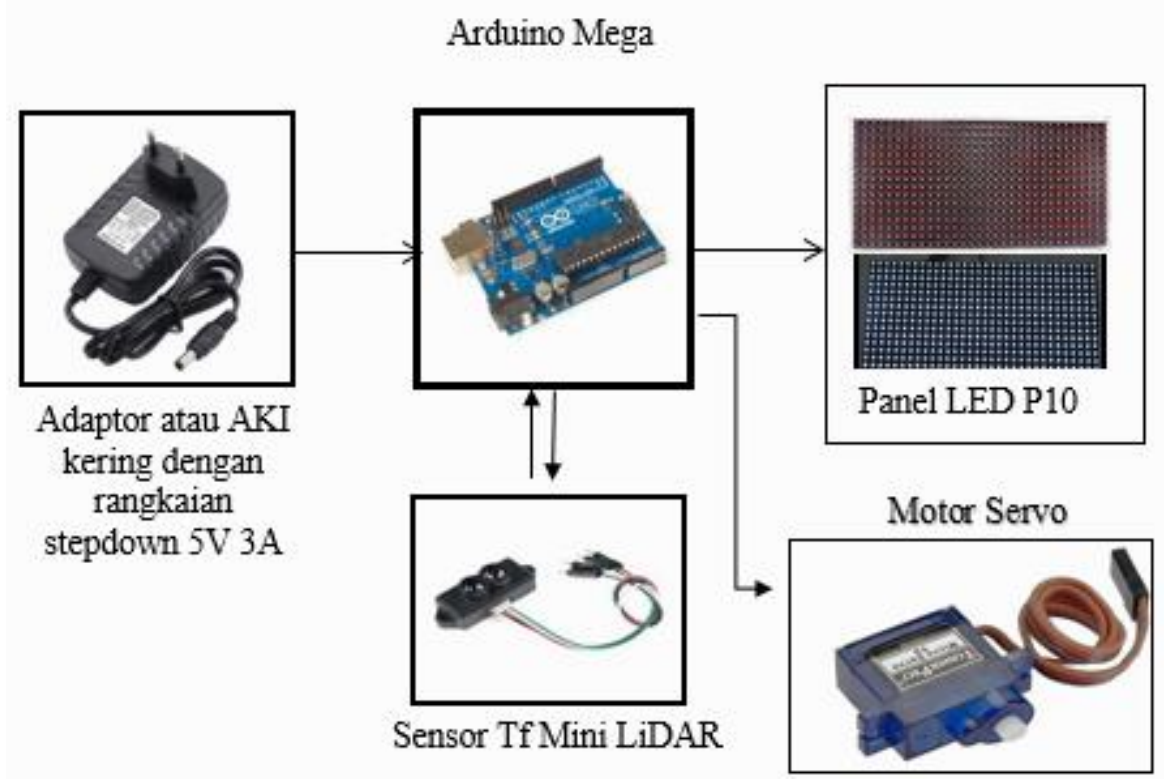

Gambar 2. Rencana Perancangan Alat

Sensor LiDAR memiliki 4 pin yang dihubungkan ke Arduino uno sebagai masukan , 4 pin pada sensor LiDAR terdiri dari TX, RX, VCC, GND. Sambungan Input port TX LiDAR terhubung ke pin 18 (Tx1) pada arduino, RX LiDAR terhubung ke pin 19 (Rx1) pada arduino.

Selanjutnya menggunakan panel LED P10 sebagai layar panel penampil peringatan pada sistem VDGS. Sambungan port yang dipasang dan skematik rangkaian ke Arduino yang digunakan ditunjukkan pada Gambar 4. 


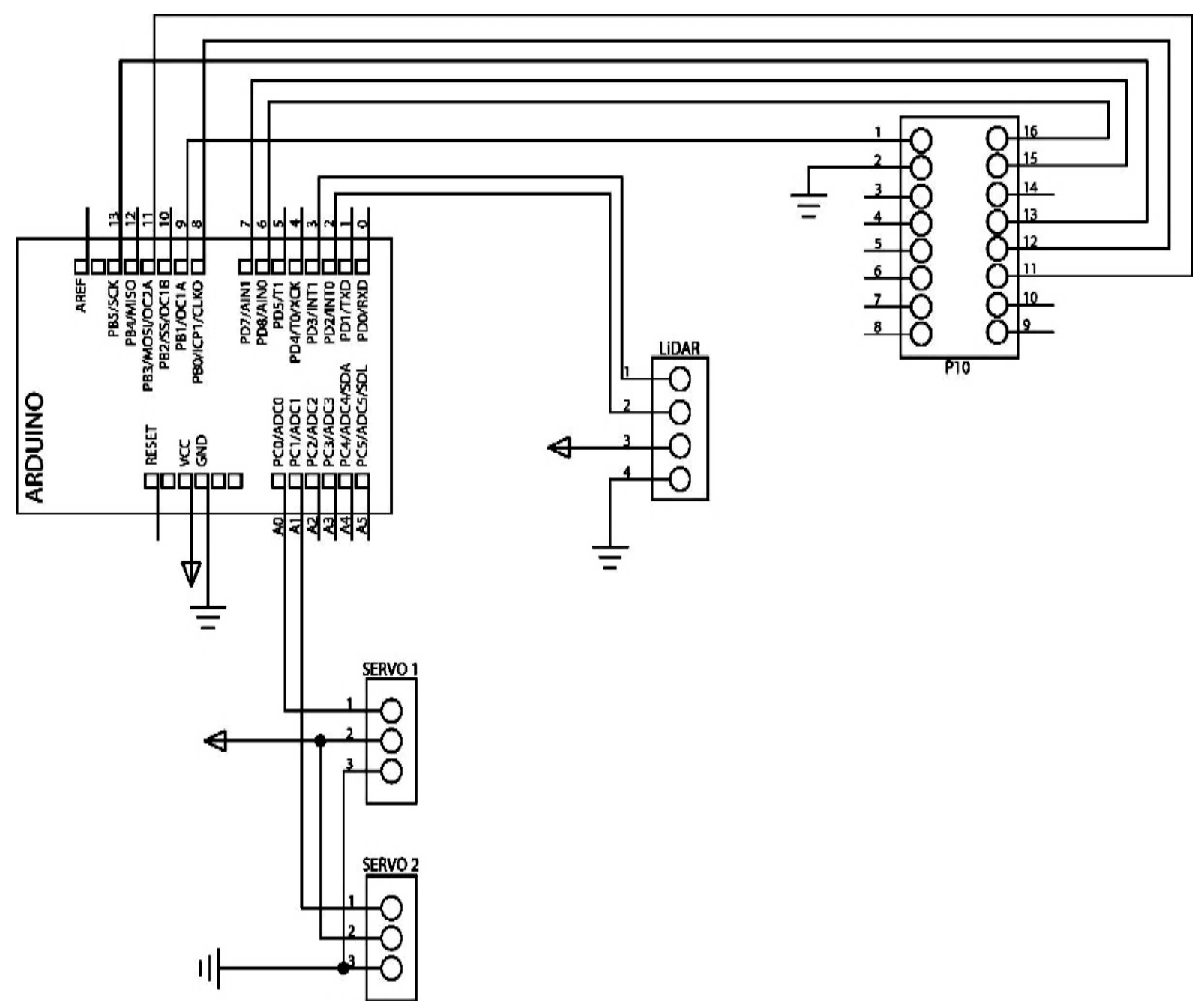

Gambar 3. Skematik Perancangan Alat

\begin{tabular}{|c|c|c|c|}
\hline \multirow{2}{*}{$\begin{array}{r}\text { OE-D9 } \\
\text { GND }\end{array}$} & 1 & 2 & \multirow{2}{*}{$\begin{array}{l}\text { A-D6 } \\
\text { B-D7 }\end{array}$} \\
\hline & 3 & 4 & \\
\hline & 5 & 6 & \\
\hline & 7 & 8 & CLK-D13 \\
\hline & 9 & 10 & SCLK-D8 \\
\hline & 11 & 12 & DATA-D11 \\
\hline & 13 & 14 & \\
\hline & 15 & 16 & \\
\hline
\end{tabular}

Gambar 4. Pin koneksi Panel LED P10

Untuk pemasangan motor servo, setiap servo memiliki 3 pin yang mana pin 2 sebagai Vin dan pin 3 sebagai Ground. Sedangkan untuk pin 1 pada motor servo merupakan pin $\mathrm{PWM} /$ signal yang mana pada servo 1 dihubungkan ke pin A0 pada arduino, dan pin 1 pada servo 2 dihubungkan ke pin A1 pada arduino.

Pada pengujian yang dilakukan, alat diuji yaitu sebagai alat bantu untuk pesawat menemukan posisi yang pas pada center line di tengah pada saat parkir di parkir stand. Pada uji coba ini untuk menemukan hasil uji yang baik. Percobaan alat dilakukan dengan pesawat Cessna 150 yang terparkir sebanyak beberapa kali yaitu dengan memposisikan pesawat berada 
di titik tengah di depan alat lalu dianalisis apakah alat mengeluarkan tanda Guidance seperti yang telah diprogram yaitu // $\$, lalu alat digeser beberapa $\mathrm{cm}$ ke sebelah kanan untuk melihat apakah alat berhasil mengeluarkan Guidance $\ll<<$ sebagai indikator pesawat terlalu ke kanan dan harus digerakkan ke kiri. Selanjutnya yang terakhir alat digeser beberapa $\mathrm{cm}$ ke kiri dari posisi tengah untuk melihat apakah alat berhasil mengeluarkan tanda Guidance $\gg>>$ sebagai indikator pesawat terlalu ke kiri dan harus digeser ke kanan agar berada pada posisi yang tepat.

Selanjutnya, diperlukannya penyesuaian alat untuk menangkap titik pengamatan sensor kebagian ujung kiri hingga ujung kanan dari sayap pesawat, hal ini diperlukan karena setiap tipe pesawat sendiri memiliki jenis ukuran panjang dan posisi sayap yang berbeda-beda. Pada percobaan kali ini karena alat yang dibuat sendiri bersifat portabel atau masih belum di patenkan dengan tiangnya, maka alat diletakkan sesuai atau sejajar dengan posis sayap pesawat yang dijadikan sebagai objek penelitian, sehingga tidak di perlukan adanya pengaturan perubahan posisi sensor melalui motor servo yang mengatur gerak vertikal sensor. Selanjutnya untuk menentukan posisi gerak sensor untuk menangkap jarak ujung sayap pesawat, maka diperlukan pengaturan gerak berapa derajat dari motor servo horizontal untuk menemukan titik tersebut.

Pada percobaan kali ini pesawat yang digunakan sebagai obyek penelitian adalah pesawat Cessna 150 bertipe highwing roda 3 dan 2 tempat duduk, yang memiliki spesifikasi sebagai berikut:

Panjang

Tinggi

$$
: \pm 7,29 \mathrm{~m}
$$

Lebar sayap kiri kekanan $: 10 \mathrm{~m}$

Tinggi sayap

$: 1,7 \mathrm{~m}$

Jarak dari hidung ke sayap : $1,5 \mathrm{~m}$

Untuk menentukan posisi gerak sensor untuk menangkap jarak ujung sayap pesawat berdasarkan Gambar 5.

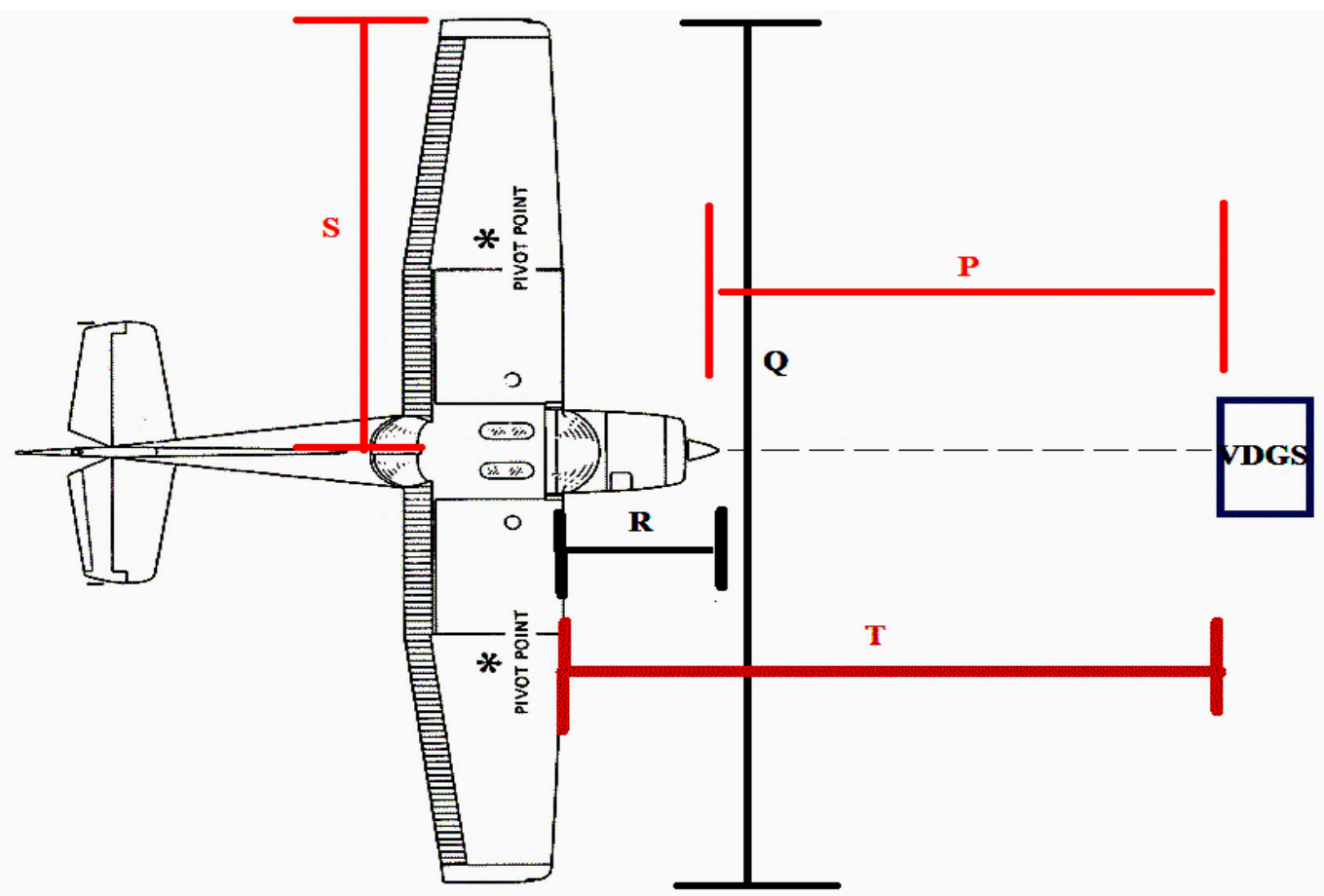

Gambar 5. Ilustrasi keadaan pesawat dan alat 
Untuk pencarian nilai $\mathrm{S}$ dan $\mathrm{T}$ menggunakan rumus sebagai berikut :

Diketahui : $\mathrm{P}=3 \mathrm{~m}$

$$
\begin{aligned}
\mathrm{Q} & =10 \mathrm{~m} \\
\mathrm{R} & =1,5 \mathrm{~m} \\
\mathrm{~S} & =\frac{\mathrm{Q}}{2} \\
& =\frac{10}{2} \\
\mathrm{~S} & =5 \mathrm{~m} \\
T & =P+R \\
& =3+1,5 \\
\mathrm{~T} & =4,5 \mathrm{~m}
\end{aligned}
$$

Selanjutnya mencari sudut dari letak alat terhadap titik tengah sayap ke ujung sayap dengan menggunakan Persamaan (3) dan ilustrasi ditunjukkan pada Gambar 6.

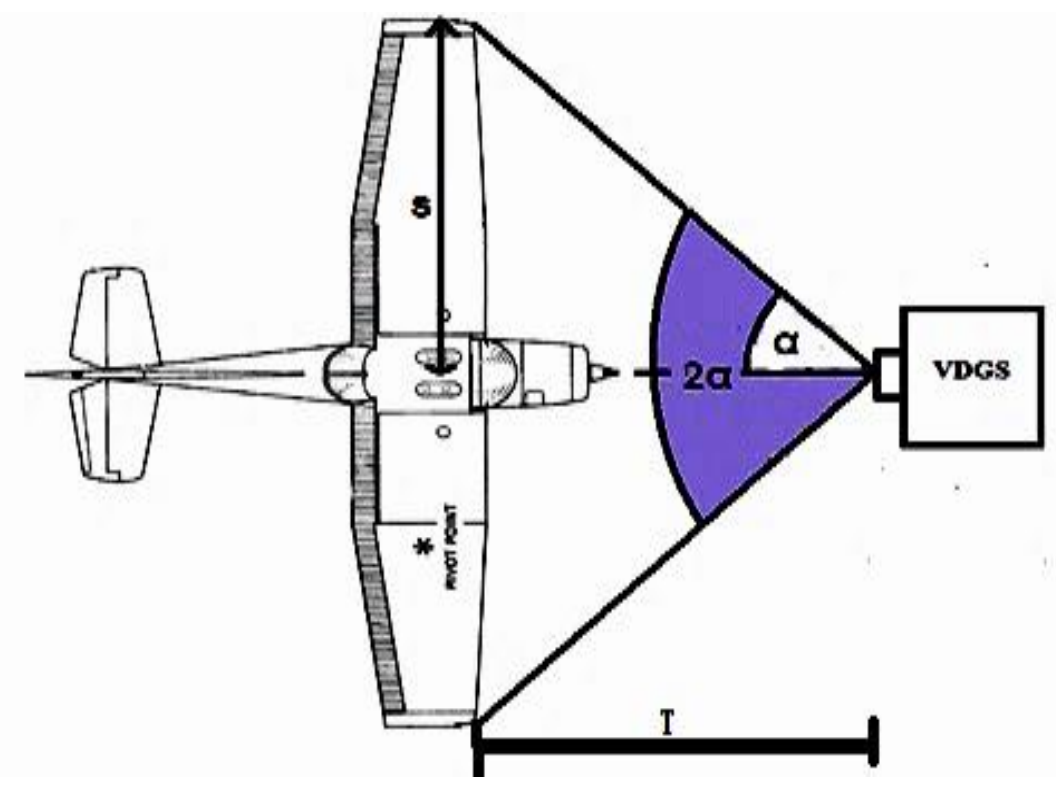

Gambar 6. Ilustrasi sudut gerak Sensor

$$
\begin{aligned}
\tan \alpha & =\frac{s}{T} \\
\tan \alpha & =\frac{5}{4,5} \\
\alpha & =48,0127875 \\
\alpha & =48
\end{aligned}
$$

Dengan demikian dapat disimpulkan agar alat bisa menangkap posisi ujung sayap pesawat dengan pada posisi terdekatnya maka direncanakan putaran motor horizontalnya diatur dengan sudut $48^{\circ}$ ke kiri dan $48^{\circ}$ ke kanan dari titik C. Selanjutnya nilai tersebut juga bisa menjadi acuan jika kita menambah titik pengamatan lagi di dalam cakupan gerak sensor 
tersebut. Di sini alat dibuat dengan memiliki 5 titik yaitu R1, R2, R3, L1, L2, L3 dan titik C sebagai titik tengah di mana dengan ketentuan titik L1 berada di sudut $30^{\circ}$ ke kiri dari titik C, $\mathrm{R} 1$ berada di sudut $30^{\circ}$ ke kanan dari titik $\mathrm{C}$ dan untuk titik R2 dan L2, $48^{\circ}$ ke kiri dari titik C sebagai L2 dan $48^{\circ}$ ke kanan dari titik C sebagai R2, selanjutnya $90^{\circ}$ dari titik C ke kanan titik R3 dan $90^{\circ}$ ke kiri merupakan titik C3. Sehingga sudut minimum pergerakan sensor dalam percobaan dengan pesawat Cessna 150 yaitu dari titik R2 ke L2 adalah sebesar $48^{\circ}+48^{\circ}=96^{\circ}$.

\section{Hasil dan Pembahasan}

\subsection{Uji Coba Pengukuran Jarak Sensor}

Dalam pengujian ini, dilakukan akuisisi pengukuran jarak sensor dengan jarak sebenarnya menggunakan meteran per 3 meter sampai jarak 12 meter. Objek yang digunakan sebagai indikator jarak adalah papan triplek dengan bidang datar dan bidang berwarna kecoklatan. Kondisi Pengukuran yang dilakukan dapat dijelaskan sebagai berikut:

a. Sensor atau alat diletakkan sejajar dengan sisi objek yang akan diukur dan tinggi dari sensor dapat di-adjust atau diubah- ubah.

b. Benda atau objek yang diukur berbentuk permukaan papan yang memiliki permukaan yang datar.

c. Pengujian alat dilakukan dengan cara papan triplek digeser mundur dari jarak 0,3-12 meter. Proses pengukuran atau pengujian alat tersebut dilakukan pada saat siang hari dan rentang jarak pengujian alat tersebut dapat dilihat pada Gambar 7.

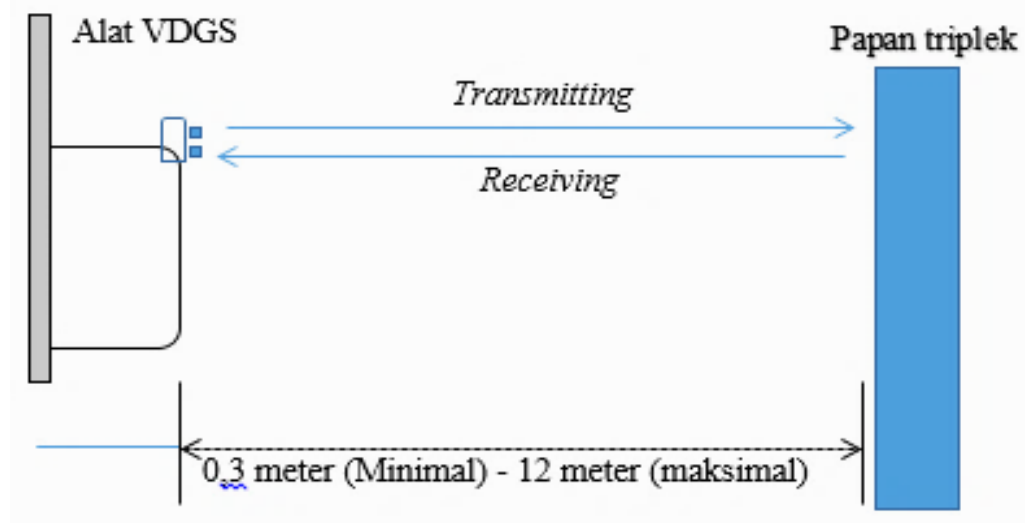

Gambar 7. Pengukuran jarak cakup sensor pada alat dengan papan triplek sebagai objek

Percobaan pertama ini dilakukan untuk mencari error pada sensor TF Mini LiDAR dalam alat ini terhadap jarak yang sebenarnya. Kemudian juga dibandingkan yang tertera alat. Dihitung presentasi error pembacaan sensor terhadap alat ukur manual (meteran) menggunakan persamaan berikut:

$\%$ error $=\left|\frac{\mathrm{Xs}-\mathrm{Xp}}{\mathrm{Xs}}\right| \times 100 \%$

Keterangan:

Xp : hasil jarak alat (m).

Xs : hasil jarak sebenarnya (m).

$\%$ error : Presentasi kesalahan antara meteran dan pengukuran sensor (\%)

Percobaan yang dilakukan dengan cara memberi penghalang berhadapan langsung dengan sensor dengan interval 0,3 meter - 12 meter pada Tabel 1 . 
Tabel 1. Pengukuran jarak oleh sensor

\begin{tabular}{c|c|c|c}
\hline Percobaan & $\begin{array}{c}\text { Jarak Sebenarnya } \\
(\mathrm{m})\end{array}$ & $\begin{array}{c}\text { Jarak Pada Alat } \\
(\mathrm{m})\end{array}$ & $\begin{array}{c}\text { Error } \\
\%\end{array}$ \\
\hline 1 & 0.3 & 0,3 & 0 \\
\hline 2 & 1 & 1 & 0 \\
\hline 3 & 2 & 2 & 0 \\
\hline 4 & 3 & 3 & 0 \\
\hline 5 & 4 & 4 & 0 \\
\hline 6 & 5 & 5 & 0 \\
\hline 7 & 6.5 & 6.5 & 0 \\
\hline 8 & 7.5 & 7.5 & 0 \\
\hline 9 & 8.52 & 8.5 & 0.2352 \\
\hline 10 & 9.57 & 9.5 & 0.7368 \\
\hline 11 & 10 & Tidak Terdeteksi & $\infty$ \\
\hline 13 & 11 & Tidak Terdeteksi & $\infty$ \\
\hline 14 & 12 & Tidak Terdeteksi & $\infty$ \\
\hline
\end{tabular}

Dari hasil pengujian sensor Tfmini LiDAR yang terdapat pada Tabel 1 dilakukan dengan pengambilan data pertama percobaan dimulai dari jarak $0.3 \mathrm{~m}$ dikarenakan berdasarkan spesifikasi dari sensor sendiri yaitu jarak $0.3 \mathrm{~m}$ kebawah masuk kedalam kondisi blind atau kondisi yang tidak mampu terbaca oleh sensor Tf mini. Berikut adalah grafik hasil dari percobaan ditampilkan pada Gambar 8.

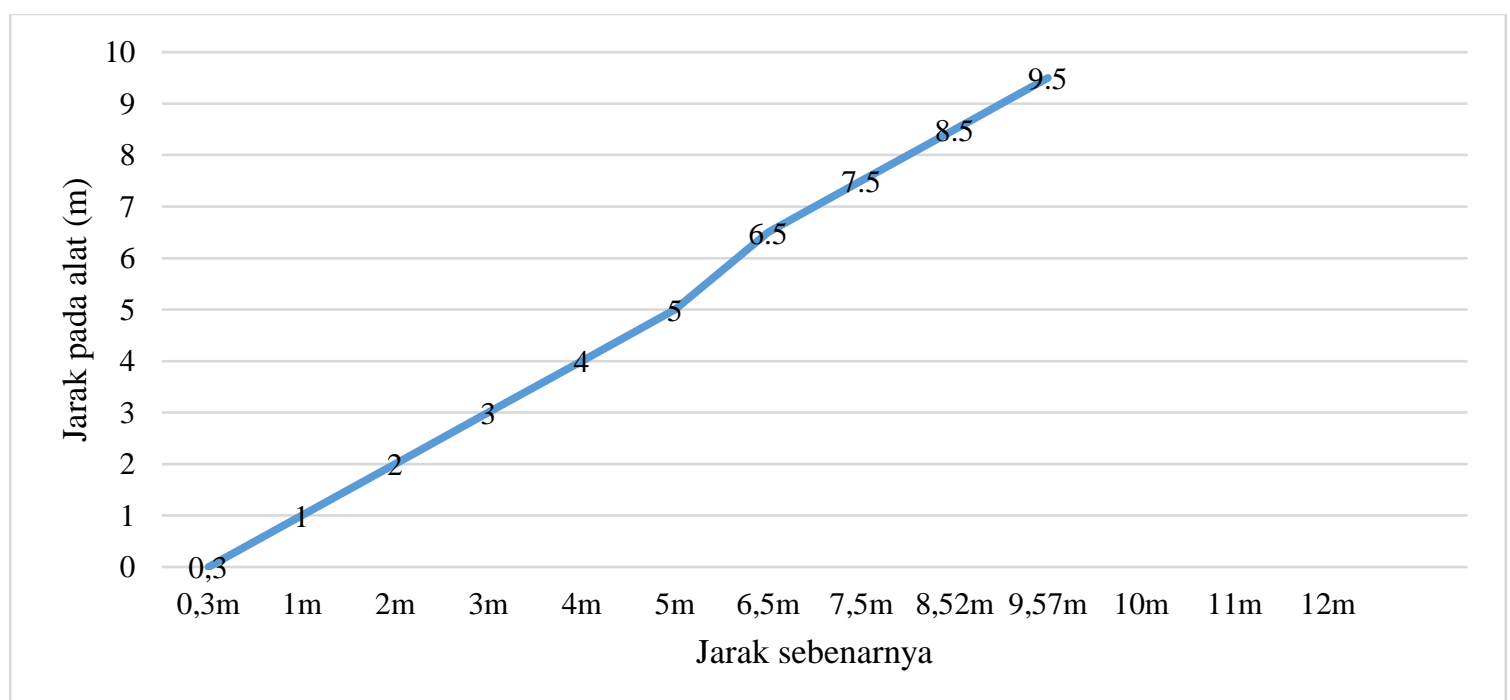

Gambar 8. Grafik hasil perbandingan pengukuran jarak alat dengan jarak sebenarnya.

Dari hasil percobaan di atas dapat disimpulkan bahwa keakuratan dari sensor memiliki rentang error sebesar 0 sampai $0.7368 \%$ dengan nilai rata-rata error yaitu:

$$
\text { ERROR RATA }- \text { RATA }=\frac{(\text { Er1+Er2+Er3+Er4+Er5+Er6+Er7+Er8+Er9+Er10 })}{10}
$$

Keterangan $: \operatorname{Er}(\mathrm{x})=$ Error pada percobaan $\mathrm{x}$ 


$$
\begin{aligned}
\text { ERROR RATA }- & \text { RATA }=\frac{(0+0+0+0+0+0+0+0+0.2352+0.7368)}{10} \\
& =\frac{(0.972)}{10} \\
& =0.0972 \%
\end{aligned}
$$

Keterangan $: \operatorname{Er}(\mathrm{x})=$ Error pada percobaan $\mathrm{x}$

Nilai tersebut merupakan nilai yang dapat dipakai dan dipercaya untuk dijadikan acuan dalam pengukuran jarak dan peringatan pada sistem VDGS.

\subsection{Uji Coba Pada Pesawar Cessna 150}

Pada uji coba kali ini posisi alat diletakkan tepat berada di titik tengah depan pesawat dengan tujuan agar setiap titik pancaran dari sensor dapat mendeteksi adanya halangan yang berjarak kurang dari 12 meter. Sesuai dengan pencarian gerak alat atau sensor diatur dengan geraknya dari titik kiri (L2) ke titik kanan(R2) harus memiliki besar sudut minimal 96. Selanjutnya alat digeser agak ke kanan dari posisi pertama yaitu di tengah, dengan tujuan untuk mengubah tangkapan pancaran sensor pada sebelah kanan agar tidak mendapatkan logika masukkan karena sensor tidak mendeteksi adanya objek dalam hal ini sayap pesawat dalam radius 12 meter dari alat. Dan terakhir alat di geser agak ke kiri dari posisi pertama yaitu dari posisi tengah, dengan tujuan untuk merubah tangkapan pancaran sensor pada sebelah kiri agar tidak mendapatkan logika masukkan karena sensor tidak mendeteksi adanya objek. Berikut hasil uji coba alat dengan menggunakan pesawat Cessna 150 sebagai objek ditunjukkan pada

\begin{tabular}{|c|c|c|c|c|c|c|c|c|}
\hline \multirow{2}{*}{ Percobaan } & \multicolumn{6}{|c|}{ Titik Pengamatan } & \multirow{2}{*}{$\begin{array}{c}\text { Hasil } \\
\text { Keluaran } \\
\text { Pada Alat }\end{array}$} & \multirow{2}{*}{$\begin{array}{c}\text { Keterangan } \\
\text { Guidance }\end{array}$} \\
\hline & L3 & $\mathrm{L} 2$ & L1 & $\mathrm{R} 1$ & $\mathrm{R} 2$ & R3 & & \\
\hline 1 & 0 & 0 & 1 & 1 & 0 & 0 & $/ / 11$ & Maju \\
\hline 2 & 0 & 1 & 1 & 1 & 1 & 0 & $/ / \backslash$ & Maju \\
\hline 3 & 0 & 0 & 0 & 1 & 1 & 0 & $\gg>>$ & Ke Kanan \\
\hline 4 & 0 & 0 & 1 & 1 & 1 & 0 & $\gg \gg$ & Ke Kanan \\
\hline 5 & 0 & 1 & 1 & 0 & 0 & 0 & $<<<<$ & Ke Kiri \\
\hline 6 & 0 & 1 & 1 & 1 & 0 & 0 & $<<<<$ & Ke Kiri \\
\hline
\end{tabular}
Tabel 2.

Tabel 2. Hasil uji coba alat dengan pesawat Cessna 150 sebagai objek

Keterangan:

1 : logika 1 mewakili sensor mendeteksi adanya penghalang dalam jarak $0,3-12 \mathrm{~m}$.

0 : logika 0 mewakili sensor tidak mendeteksi adanya penghalang dalam jarak 0,3-12m.

// : Hasil keluaran pada alat sudah berada pada bagian tengah.

$\ll<<$ : Hasil keluaran alat ketika pesawat berada lebih ke kanan

〉>> : Hasil keluaran alat ketika pesawat berada lebih ke kiri

Berikut gambar ilustrasi percobaan 1 dan 2 pada tabel dimana posisi pesawat saat berada ditengah ditunjukkan pada Gambar 9. 


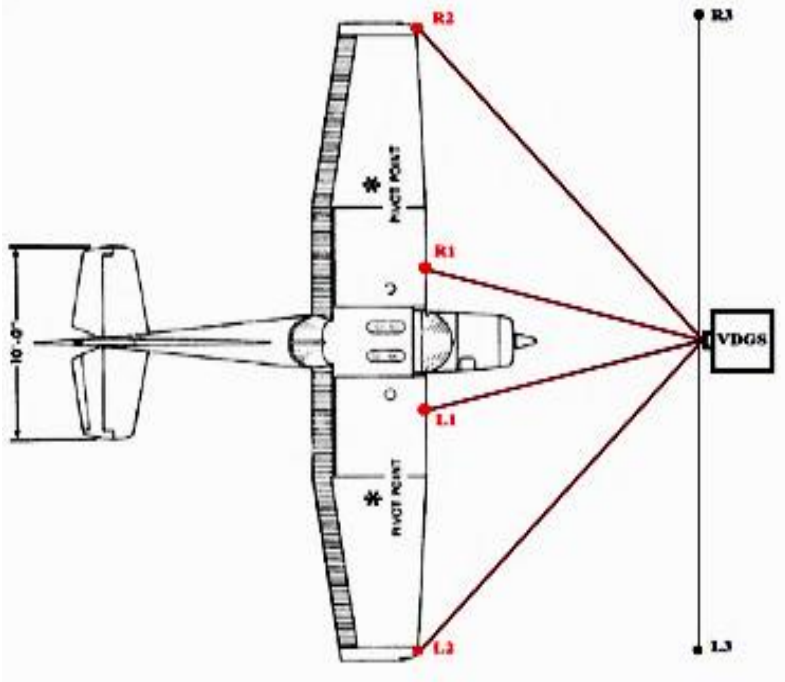

1

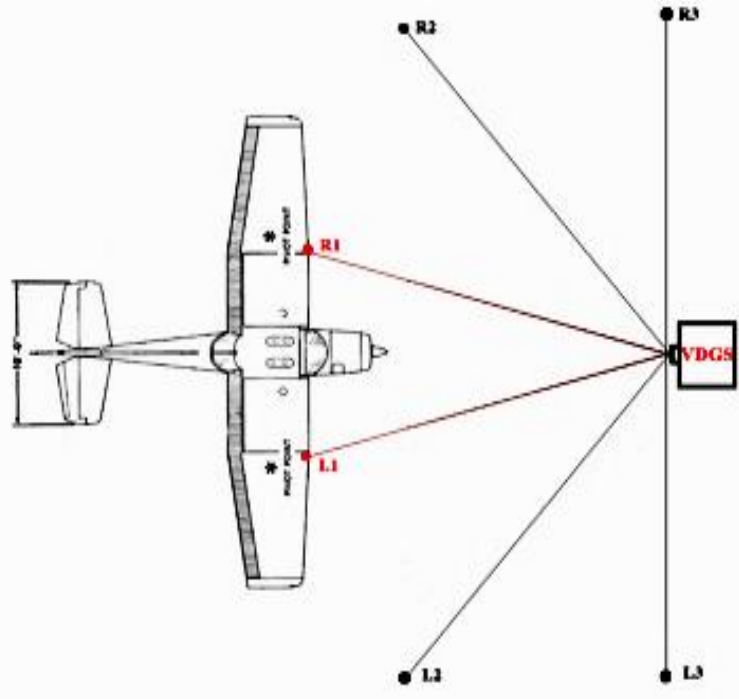

2

Gambar 9. Ilustrasi Pesawat Berada Tepat di Tengah

Berdasarkan tabel percobaan dengan hasil tengah di atas, dapat disimpulkan hasil pemrograman dari alat sesuai dengan yang diharapkan. Dari percobaan tersebut logika 1 mewakili sensor yang mendeteksi adanya penghalang pada tiap-tiap titik pancar yaitu sayap dari pesawat yang berjarak di bawah 12 meter sesuai dengan spesifikasi sensor LiDAR yang di gunakan. Sedangkan logika 0 mewakili sensor yang tidak mendeteksi adanya halangan pada setiap titik pancar dalam radius 12 meter seperti tertera pada Tabel 2. Berikut hasil dari tampilan alat ditunjukkan pada Gambar 10.

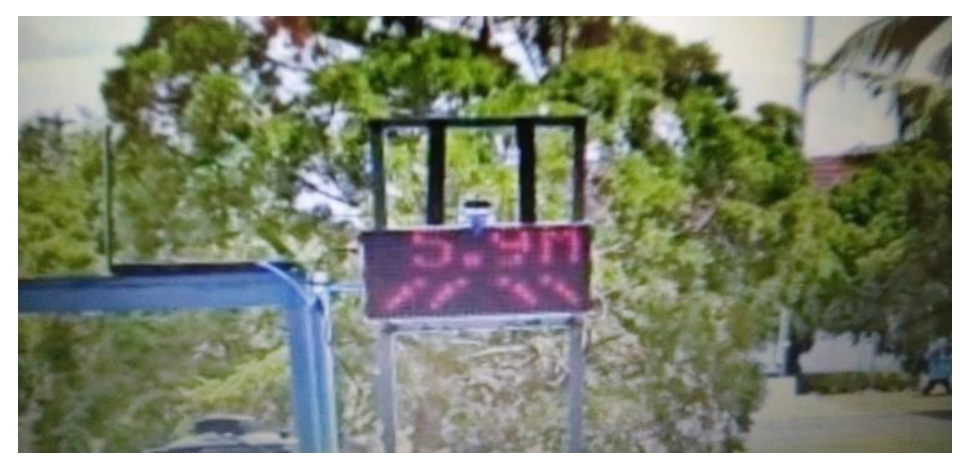

Gambar 10. Hasil Tampilan Alat saat Pesawat berada di Tengah

Selanjutnya untuk hasil dari Percobaan 3 dan 4 pada Tabel di mana posisi pesawat saat berada lebih ke kiri ditunjukkan pada Gambar 11.

Ketika pesawat digeser lebih ke kiri maka secara otomatis sayap dari objek juga akan bergeser, hal ini menyebabkan titik pancar L1, L2, dan L3 menjadi tidak terhalang sehingga menjadikannya yang semula berlogika 1 menjadi berlogika 0 sehingga hasil tampilan dari alat yaitu perintah agar pesawat digerakkan lebih ke kanan (>>>), begitu pun ketika alat digeser hingga titik L1, R1, dan R2 berubah menjadi logika 1 dan juga ketika posisi alat digeser hingga titik L2, L1, LR1, R2, dan R3 berubah menjadi berlogika 1 dan hasil tampilan dari alat menjadi tampilan Guidance (>>>) seperti Gambar 12. 


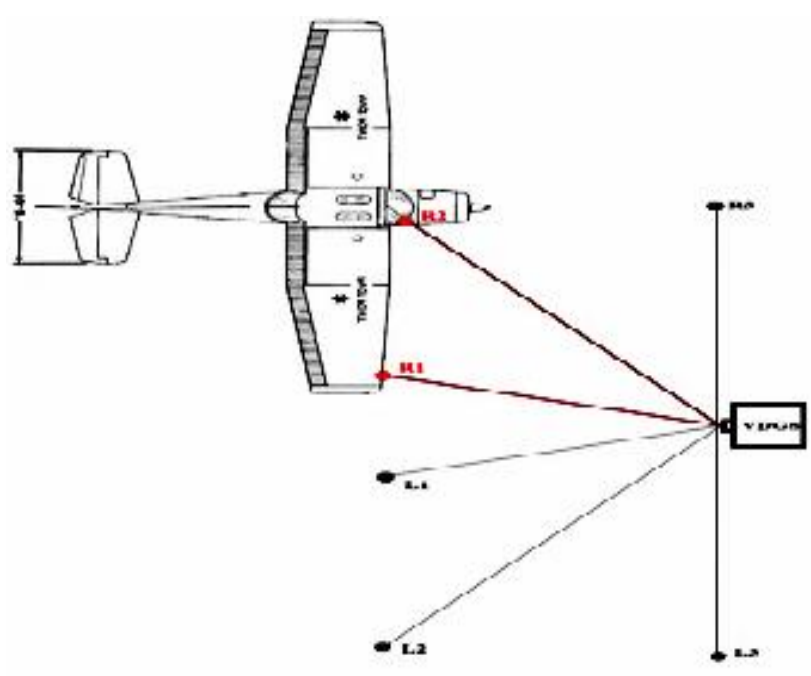

3

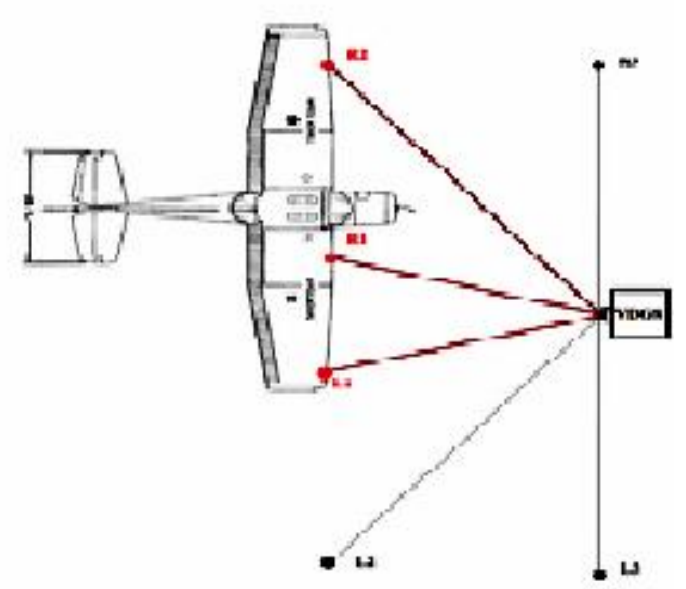

4

Gambar 11. Ilustrasi Pesawat Berada di Lebih ke Kiri

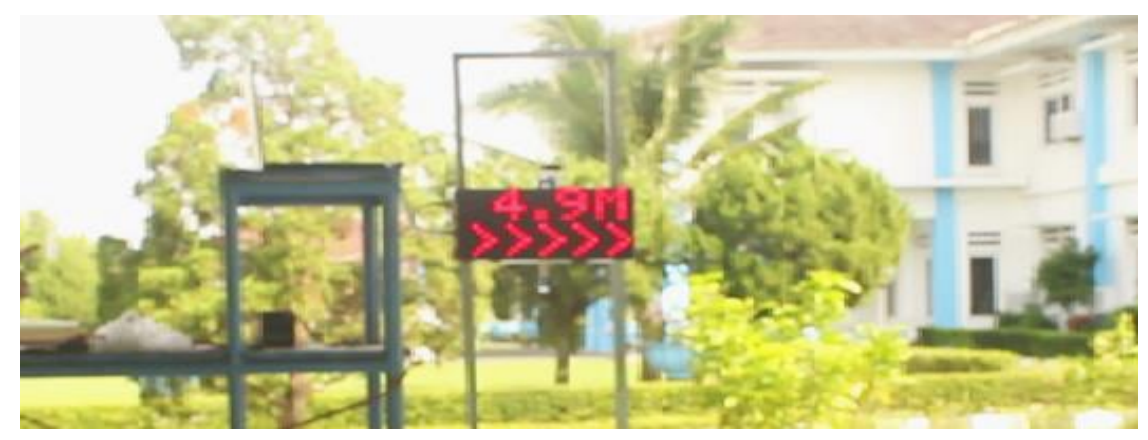

Gambar 12. Hasil tampilan alat ketika pesawat lebih ke kiri

Dan untuk hasil dari Percobaan 5 dan 6 pada tabel di mana posisi pesawat saat berada lebih ke kanan ditunjukkan pada Gambar 13.

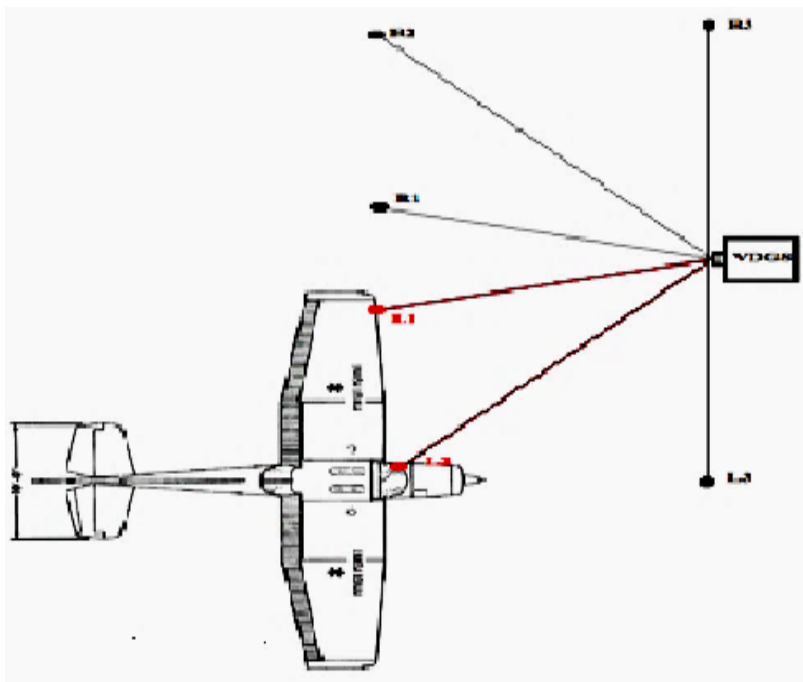

5

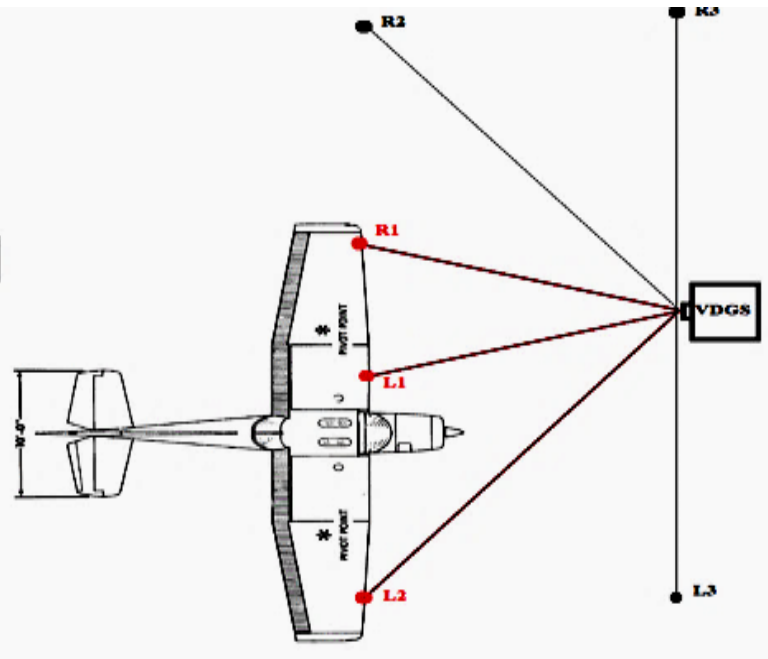

6

Gambar 13. Ilustrasi pesawat berada lebih ke kanan 
Berdasarkan Tabel 2 percobaan di atas, ketika pesawat digeser lebih ke kanan maka secara otomatis sayap dari objek juga akan bergeser menyebabkan titik pengamatan R1, R2, dan R3 menjadi tidak terhalang sehingga menjadikannya semula berlogika 1 menjadi berlogika 0 , sehingga hasil tampilan dari alat yaitu perintah agar pesawat digerakkan lebih ke kiri $(\ll<<<)$, begitu pun ketika alat digeser hingga titik pengamatan L2, L1, dan R1 berubah menjadi logika 1 dan juga ketika titik pancar L3, L2, L1, R1, dan R2 berubah menjadi logika 1 dan hasil tampilan dari alat menjadi tampilan Guidance $(\ll<<)$ seperti Gambar 14.

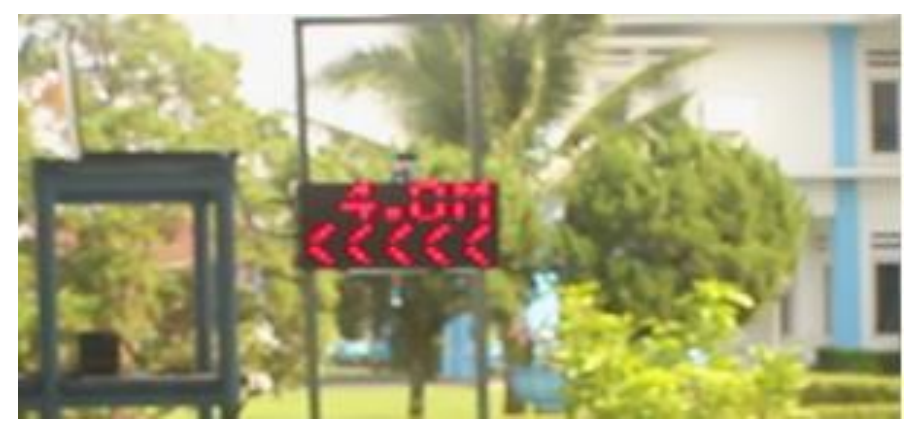

Gambar 14. Hasil tampilan alat ketika pesawat lebih ke kanan

\section{Kesimpulan}

Berdasarkan hasil perancangan alat bantu parkir pesawat (VDGS) untuk mendeteksi gerak longitudinal pesawat pada saat parkir yang menggunakan sensor TF mini LiDAR ini bekerja dengan baik dan sesuai dengan yang diharapkan, alat ini berhasil memberikan informasi berupa tampilan perintah Guidance untuk menggerakkan pesawat ke kiri atau ke kanan untuk menemukan posisi center line yang benar. Hasil pengukuran jarak yang ditampilkan oleh alat dapat dikatakan cukup akurat meskipun pada saat uji coba alat hanya mampu menangkap objek sejauh 10 meter, error yang didapat dari uji coba pengukuran jarak alat dan jarak sebenarnya memiliki rentang dari 0 hingga $0,7368 \%$ dan juga memiliki rata-rata error $0.0972 \%$.

\section{Daftar Pustaka}

[1] Boṡtjian K. (2016). Aircraft Docking Guidance System. Aerodrom Ljubljana: Slovenia.

[2] Dermawan, D., \& Purnomo, M. J. (2015). Perancangan Tampilan Visual Docking Guidance System (VDGS) pada Sistem Parkir Pesawat Terbang. Angkasa: Jurnal Ilmiah Bidang Teknologi, 7(2), 181-191.

[3] Gunung A.T. (2019). Sistem Pemetaan Ruang 3D Menggunakan Sensor LiDAR (Light Detection and Ranging), Teknik Elektro Sekolah Tinggi Teknologi Adisutjipto: Yogyakarta.

[4] Honeywell. (2013). Advanced Visual Docking Guidance System. Honeywell International Inc: New Jersey.

[5] Kementrian Perhubungan, (2015). Peraturan Direktur Jendral Perhubungan Udara. Kementrian Perhubungan: Jakarta.

[6] Muhammad Ilham, H. (2018). Rancang Bangun Model Pendeteksi Jarak Pada Pesawat Sebagai Peringatan Potensi Tabrakan Di Apron Dalam Penerbangan Perintis Dengan Menggunakan Sensor SR04T. Teknik Elektro Sekolah Tinggi Teknologi Adisutjipto: Yogyakarta.

[7] Sidiq Wijanarko, (2019). Rancang Bangun Alat Ukur dan Peringatan Pada Visual 
Docking Guidance System (VDGS) Menggunakan Sensor Light Detection and Ranging (LiDAR) Berbasis Mikrokontroler ATMEGA 328. Teknik Elektro Sekolah Tinggi Teknologi Adisutjipto: Yogyakarta.

[8] Sunandar, I., \& Syarifudin, D. (2014). LiDAR: Pengindraan Jauh Sensor Aktif dan Aplikasinya di Bidang Kehutanan. Jurnal Planologi UNPAS, 1(2), 145-154.

[9] Wijanarko, S., Waluyo, C. B., \& Dermawan, D. (2019). Rancang Bangun Alat Ukur Jarak dan Peringatan pada Visual Docking Guidance System menggunakan Sensor Lidar. AVITEC, 1(1), 39-52. 